\title{
AVALIAÇÃO DOS MICRORGANISMOS PRESENTES NOS FRUTOS DA MACAÚBA (ACROCOMIA ACULEATA) APÓS DIFERENTES TRATAMENTOS PÓS-COLHEITA
}

\author{
L. A. L. QUEIROZ ${ }^{1}$, C. S. NASCIMENTO ${ }^{1}$, SANTOS, V. L. ${ }^{2}$, E. C. CREN $^{1}$ e M. H. C. \\ ANDRADE $^{1}$ \\ ${ }^{1}$ Universidade Federal de Minas Gerais, Escola de Engenharia, Departamento de Engenharia \\ Química \\ ${ }^{2}$ Universidade Federal de Minas Gerais, Instituto de Ciências Biológicas, Departamento de \\ Microbiologia \\ E-mail: lorenaqueiroz84@yahoo.com.br
}

\begin{abstract}
RESUMO - No estado de Minas Gerais, em função da forte presença de maciços naturais, a cultura da Macaúba tem sido considerada importante do ponto de vista econômico, devida à elevada produtividade de óleo vegetal com potencial para produção de biodiesel e outros fins. Uma das dificuldades está associada com a forma de colheita dos frutos, cujo ponto ideal de maturação ocorre com o desprendimento do cacho. Ao entrar em contato com o chão, os frutos sofrem contaminação por microrganismos, e consequente deterioração de quase todas as partes, comprometendo a qualidade do fruto e seus produtos. O objetivo deste trabalho foi avaliar os microrganismos presentes na casca e polpa do fruto após diferentes tratamentos póscolheita e após 30 dias de armazenamento. Identificou-se uma diversidade de leveduras, bactérias e fungos, sendo maior na casca em relação à polpa em todos os casos. Após o armazenamento verificou-se uma predominância de fungos na polpa, e de bactérias e leveduras na casca.
\end{abstract}

\section{INTRODUÇÃO}

A Macaúba (Acrocomia aculeata) é a palmeira de maior distribuição no Brasil, estando presente em quase todas as regiões do território brasileiro, sendo que os povoamentos naturais mais densos localizam-se em Minas Gerais, Goiás e nos estados do Mato Grosso (CETEC, 1983). $\mathrm{O}$ fruto da macaúba possui óleo em todas as partes constituintes, exceto no endocarpo, o que o torna uma promissora fonte de óleo vegetal. Segundo Nucci (2007) sua capacidade de produção de óleo vegetal pode chegar a quatro mil litros por hectare por ano, sendo que através de plantios racionais e de programas de melhoramento este valor pode aumentar consideravelmente.

O principal problema em relação ao óleo bruto de macaúba é a elevada acidez. Após a maturação completa, os frutos desprendem-se do cacho e caem no chão, sofrendo contaminação por microrganismos com deterioração e alteração em praticamente todas as partes do fruto, o que compromete a qualidade do óleo (MOTA et al., 2011). A microflora, representada em grande parte por fungos, contém microrganismos lipolíticos que hidrolisam os triglicerídeos presentes na polpa, levando a um aumento do teor de ácidos graxos livres no óleo (LINARD, 1981; SILVA, 2007). 
Pouco se sabe ainda sobre a conservação pós-colheita do fruto da Macaúba e a extração do óleo é realizada aplicando-se tecnologias adaptadas de outras oleaginosas. Para superar as principais dificuldades no processamento dessa oleaginosa, são necessários estudos específicos de conservação pós-colheita e obtenção de óleo de qualidade (MARTINS, 2013). Diferentes métodos podem ser empregados com a finalidade de diminuir a atividade metabólica e minimizar o processo de deterioração dos frutos, entre eles a sanitização com hipoclorito de sódio e a secagem.

Visando desenvolver novas estratégias para armazenar os frutos da Macaúba com qualidade, permitindo assim o uso do óleo para seus diversos fins, o objetivo deste trabalho foi avaliar os microrganismos presentes na casca e polpa do fruto após diferentes tratamentos pós-colheita e após 30 dias de armazenamento.

\section{MATERIAL E MÉTODOS}

Os frutos foram coletados em palmeiras localizadas no campus Belo Horizonte da Universidade Federal de Minas Gerais na safra 2012/2013. Ressalta-se que os frutos foram coletados com no máximo sete dias de queda. Para avaliar o efeito de diferentes tratamentos póscolheita, os frutos foram divididos em três lotes:

- lote 0 - frutos coletados no chão, armazenados sem limpeza prévia;

- lote 2 - frutos coletados no chão, lavados com água, imersos rapidamente em solução de hipoclorito de sódio $2 \%$ e secos à temperatura ambiente;

- lote 3 - frutos coletados no chão, lavados com água, imersos rapidamente em solução de hipoclorito de sódio $2 \%$ e secos na estufa a $60^{\circ} \mathrm{C}$ por $24 \mathrm{~h}$.

Foram selecionados aleatoriamente seis frutos de cada lote, sendo esses agrupados em dupla e condicionados em sacos plásticos, totalizando três sacos plásticos com dois cocos em cada lote.

Para a quantificação dos microrganismos presentes na casca do fruto, foram adicionados 100 ml de água salina a $1 \%$ em cada saco plástico, e estes posteriormente foram colocados em um banho ultrassônico por cerca de cinco minutos, promovendo a dispersão dos microrganismos presentes na casca para a água salina. Em seguida, em ambiente estéril, foi retirado $1 \mathrm{ml}$ da água salina para preparar as diluições de $10^{-1}, 10^{-2}$ e $10^{-3}$, sendo transferido $100 \mu \mathrm{L}$ de cada diluição para placas de Petri, contendo os meios TSA (isolamento de bactérias), BDA (isolamento de fungos) e YM (isolamento de leveduras), previamente esterilizados. Para o isolamento das bactérias foi adicionado no meio de cultura uma solução de antifúngico Benomil 0,05 g/L e para o isolamento de fungos e leveduras foi adicionado um antibacteriano Cloranfenicol $0,2 \mathrm{~g} / \mathrm{L}$. As placas inoculadas foram incubadas em estufas a $37^{\circ} \mathrm{C}$ por $24 \mathrm{~h}$ para o crescimento das bactérias, a $25-28^{\circ} \mathrm{C}$ por $72 \mathrm{~h}$ para o crescimento das leveduras e a $25-28^{\circ} \mathrm{C}$ por 5-7 dias para o crescimento dos fungos.

Para a quantificação dos microrganismos presentes na polpa, os frutos que estavam imersos na água salina foram lavados com detergente neutro e em seguida, secos com papel toalha, diminuindo assim a contaminação da polpa pela casca. Cerca de $1 \mathrm{~g}$ de polpa foi transferida para 9 $\mathrm{mL}$ de solução salina $1 \%$. Na sequencia foi seguido o mesmo procedimento adotado na casca. Os diferentes morfotipos encontrados foram enumerados e classificados quanto as seguintes características: bactérias (cor, brilho, borda, aspecto); fungos (cor, borda, aspecto, reverso); leveduras (cor, brilho, borda, aspecto). 


\section{RESULTADOS E DISCUSSÃO}

O número de morfotipos encontrados em cada parte (casca e polpa) nos frutos frescos (tempo 0) e nos frutos armazenados (tempo 30) podem ser vistos na Tabela 1.

Tabela 1 - Número de morfotipos em frutos da safra 2012/2013.

\begin{tabular}{c|c|ccc|ccc}
\hline \multicolumn{3}{c}{} & \multicolumn{3}{c|}{ Tempo 0 } & \multicolumn{3}{c}{ Tempo 30 } \\
\hline \multirow{3}{*}{ Casca } & Bactéria & Fungo & Levedura & Bactéria & Fungo & Levedura \\
\hline \multirow{3}{*}{ Polpa } & Lote 0 & 2 & 8 & 3 & 18 & 12 & 1 \\
& Lote 2 & 1 & 1 & 2 & 3 & 0 & 1 \\
& Lote 3 & 2 & 0 & 0 & 0 & 0 & 1 \\
& Lote 0 & 3 & 0 & 0 & 1 & 2 & 0 \\
& Lote 2 & 1 & 0 & 2 & 0 & 2 & 1 \\
& Lote 3 & 1 & 0 & 0 & 0 & 2 & 1 \\
\hline
\end{tabular}

Os resultados indicam que houve um aumento expressivo da diversidade de fungos e bactérias na casca no período de 30 dias de armazenamento em temperatura ambiente, para os frutos que não sofreram nenhum tratamento prévio, lote zero, e que em contrapartida houve uma diminuição da diversidade de levedura. Ainda, considerando a casca do fruto, os resultados indicam que ambos os tratamentos realizados foram eficazes contra o aumento da diversidade de fungos e bactérias na casca, mesmo tendo sido constatado o aumento da diversidade de bactéria de 1 para 3 no lote 2, uma vez que trata-se da análise de diferentes frutos.

Considerando a analise da polpa do fruto, pode-se relatar que os frutos no tempo zero apresentavam pequena diversidade de bactérias e leveduras e nenhum tipo de fungo foi encontrado. Assim, mesmo considerando a coleta de frutos do chão, conclui-se que as polpas dos frutos se encontravam em estado adequado de preservação em relação à contaminação microbiana. Após o período de 30 dias de armazenamento, a polpa dos frutos apresentaram apenas dois tipos de fungos, independentemente do tratamento efetuado. Pode-se afirmar ainda, que os tratamentos efetuados preservaram as polpas dos frutos no tocante a eliminação das bactérias e aumento da diversidade de fungos e leveduras. Outro resultado a ser destacado é que o simples fato de se retirar os frutos do chão, com no máximo sete dias de queda, e armazená-los em cestos perfurados no ambiente do laboratório, foi suficiente para a preservação da polpa com relação ao aumento da diversidade de bactérias, fungos e leveduras.

A literatura é o suporte para a explicação desses resultados. A capacidade de sobrevivência ou de multiplicação dos microrganismos que estão presentes em um alimento depende de uma série de fatores. As atividades dos microrganismos, bem como, os mecanismos de sobrevivência encontrados pelos mesmos, estão interligadas com condições ambientais, ou seja, as condições de conforto ambiental favoráveis para a manutenção e permanência desses grupos (CAMPBELL e NORMAN, 1998). Outros fatores estão relacionados com as características próprias do alimento (fatores intrínsecos), com a atividade de água (Aa ou Aw), a acidez $(\mathrm{pH})$, o potencial de oxiredução (Eh), composição química, fatores antimicrobianos naturais, e interações entre microorganismos presentes (TORTORA et al., 2004). Por influência desses fatores, por si só ou associados a outros de natureza ambiental, as alterações de alimentos são, às vezes, sensivelmente modificadas a tal ponto, que a alteração desaparece, sendo substituída por outra de forma 
diferente. Um exemplo da ação combinada destes fatores no crescimento de microrganismos é que os fungos se desenvolvem mais que as bactérias e leveduras, no alimento com pequeno teor de umidade (EVANGELISTA, 1994).

O número de microrganismos foi determinado em unidades formadoras de colônias (UFC) por grama de massa seca, uma vez que os lotes apresentavam umidades diferentes, principalmente considerando o lote que passou por processo de secagem parcial. As quantidades totais de microrganismos detectadas na casca e polpa logo após a coleta e tratamento, e após trinta dias de armazenamento estão apresentadas na Tabela 2.

Tabela 2 - Quantidade total de microrganismos (UFC/g $\mathrm{g}_{\text {massa seca }}$ ).

\begin{tabular}{lcc|cc}
\hline & \multicolumn{2}{c|}{ Casca } & \multicolumn{2}{c}{ Polpa } \\
& Tempo 0 & Tempo 30 & Tempo 0 & Tempo 30 \\
\hline \hline Lote 0 & $2,9 \times 10^{3}$ & $2,0 \times 10^{3}$ & $8,8 \times 10^{1}$ & $5,1 \times 10^{2}$ \\
Lote 2 & $1,7 \times 10^{2}$ & $4,1 \times 10^{1}$ & $3,2 \times 10^{3}$ & $1,9 \times 10^{3}$ \\
Lote 3 & $2,3 \times 10^{1}$ & $1,2 \times 10^{1}$ & $2,1 \times 10^{1}$ & $8,3 \times 10^{3}$ \\
\hline
\end{tabular}

Considerando a casca e os diferentes tratamentos nos tempo zero e 30 dias de armazenamento, pode-se afirmar que o quantitativo de microrganismos foi maior para o lote que não sofreu nenhum tratamento e foi menor para o lote que sofreu tratamento de higienização e secagem parcial. Com relação ao número de microrganismos no período de armazenamento para cada tipo de tratamento, pode-se relatar que não houve aumento, sendo assim, a simples retirada do solo e colocação em outras condições é uma orientação a ser seguida.

Em relação à polpa no tempo zero pode-se afirmar um estado de menor ataque microbiano quando comparado à casca, corroborando com o relato da diversidade de microrganismos. Em contrapartida, ao se comparar o tempo zero com o tempo 30, houve um aumento expressivo da microbiota da polpa com o armazenamento. Exceção a este comportamento foi observada no lote 2 e a provável explicação recai nos frutos analisados que foram escolhidos ao acaso: os avaliados deveriam estar em estado mais avançado de deterioração.

Os resultados deste trabalho encontram respaldo na literatura pertinente e no que se observa visualmente: o tempo de armazenamento contribui para a ação de microrganismos na polpa. Segundo Brackett (1987), o aumento na taxa de deterioração do fruto é decorrente da transferência da microbiota da casca para a polpa, onde os microrganismos encontram condições favoráveis ao seu crescimento. Adicionalmente, pode-se observar que os tratamentos podem ter provocado algum tipo de alteração da casca facilitando a contaminação da polpa do fruto. Com o intuito de avaliar dois métodos de sanitização (imersão em água fervente seguida de secagem ao sol e imersão em água fervente e seco em estufa a $120^{\circ} \mathrm{C}$ ), Silva et al. (2010) concluíram que a contaminação dos frutos da macaúba ocorre de maneira gradual, com os microrganismos penetrando pelas áreas susceptíveis do fruto, como os orifícios, e infestando gradualmente toda a polpa, causando alterações na sua estrutura, cor, sabor, cheiro e composição química.

De uma forma geral, os resultados indicam que não houve efeito efetivo dos tratamentos utilizados na redução de microrganismos nos frutos da macaúba armazenados em temperatura ambiente, uma vez que após 30 dias foi verificada a presença de microrganismos em todos os 
lotes, tanto na casca como na polpa. Silva et al. (2010) também verificou um aumento da quantidade de microrganismos presentes na polpa da macaúba durante o armazenamento.

Em relação ao grupo de microrganismos, a quantidade de bactérias, fungos e leveduras, logo após cada tratamento e após os trinta dias de armazenamento, é apresentada na Tabela 3.

Tabela 3 - Quantidade bactérias, fungos e leveduras (UFC/ gmassa seca $_{\text {) }}$

\begin{tabular}{|c|c|c|c|c|c|c|c|}
\hline & \multicolumn{3}{|c|}{ Tempo 0} & \multicolumn{3}{|c|}{ Tempo 30} \\
\hline & & Bactérias & Fungos & Leveduras & Bactérias & Fungos & Leveduras \\
\hline \multirow{3}{*}{ Casca } & Lote 0 & $2,0 \times 10^{3}$ & $1,1,6 \times 10^{2}$ & $7,4 \times 10^{2}$ & $8,9 \times 10^{2}$ & $7,0 \times 10^{2}$ & $\overline{4} 4,4 \times 10^{2}$ \\
\hline & Lote 2 & $0,6 \times 10^{1}$ & $0,6 \times 10^{1}$ & $1,6 \times 10^{2}$ & $1,2 \times 10^{1}$ & 0 & $2,9 \times 10^{1}$ \\
\hline & Lote 3 & $2,3 \times 10^{1}$ & 0 & 0 & 0 & 0 & $1,2 \times 10^{1}$ \\
\hline \multirow{3}{*}{ Polpa } & Lote 0 & $8,8 \times 10^{1}$ & 0 & 0 & $2,4 \times 10^{1}$ & $4,8 \times 10^{2}$ & 0 \\
\hline & Lote 2 & $3,6 \times 10^{1}$ & 0 & $3,1 \times 10^{3}$ & 0 & $4,2 \times 10^{2}$ & $1,4 \times 10^{3}$ \\
\hline & Lote 3 & $2,1 \times 10^{1}$ & 0 & 0 & 0 & $8,3 \times 10^{3}$ & $2,7 \times 10^{1}$ \\
\hline
\end{tabular}

O percentual que cada grupo de microrganismo representa em relação à quantidade total encontra-se nas Figuras 1 e 2. Destaca-se que para os cálculos dos percentuais foram utilizados os valores exatos.

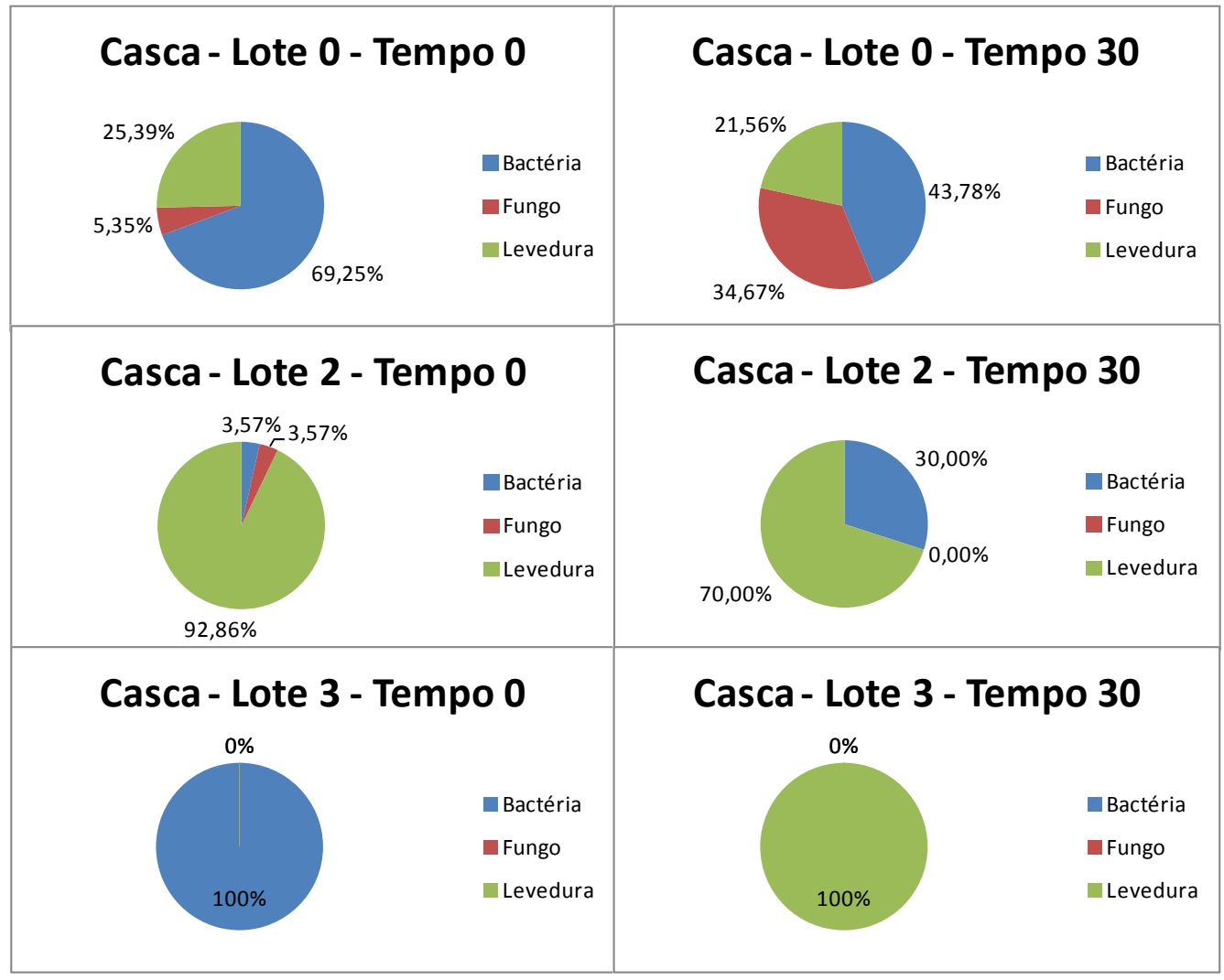

Figura 1- Percentual de microrganismos na casca. 
$\mathrm{Na}$ casca, pode-se observar que, tanto após a coleta e tratamento, quanto após o período de armazenamento, houve uma predominância de bactérias e leveduras. No lote 2, as leveduras predominaram, o que pode ser um indicativo de que a lavagem seguida de imersão de hipoclorito é eficiente na redução de bactérias e fungos presentes na casca. A lavagem seguida de imersão em hipoclorito de sódio e secagem (lote 3) mostrou-se efetiva em relação a remoção de leveduras e fungos, pois neste lote não foi constatado a presença destes microrganismos na casca. Entretanto, após o armazenamento as leveduras representam a maior parte da microbiota presente na casca. Os dois tratamentos utilizados mostraram-se eficientes em relação aos fungos, já que tanto no tempo “0”como no tempo "30” a presença de fungos é mínima ou inexistente.

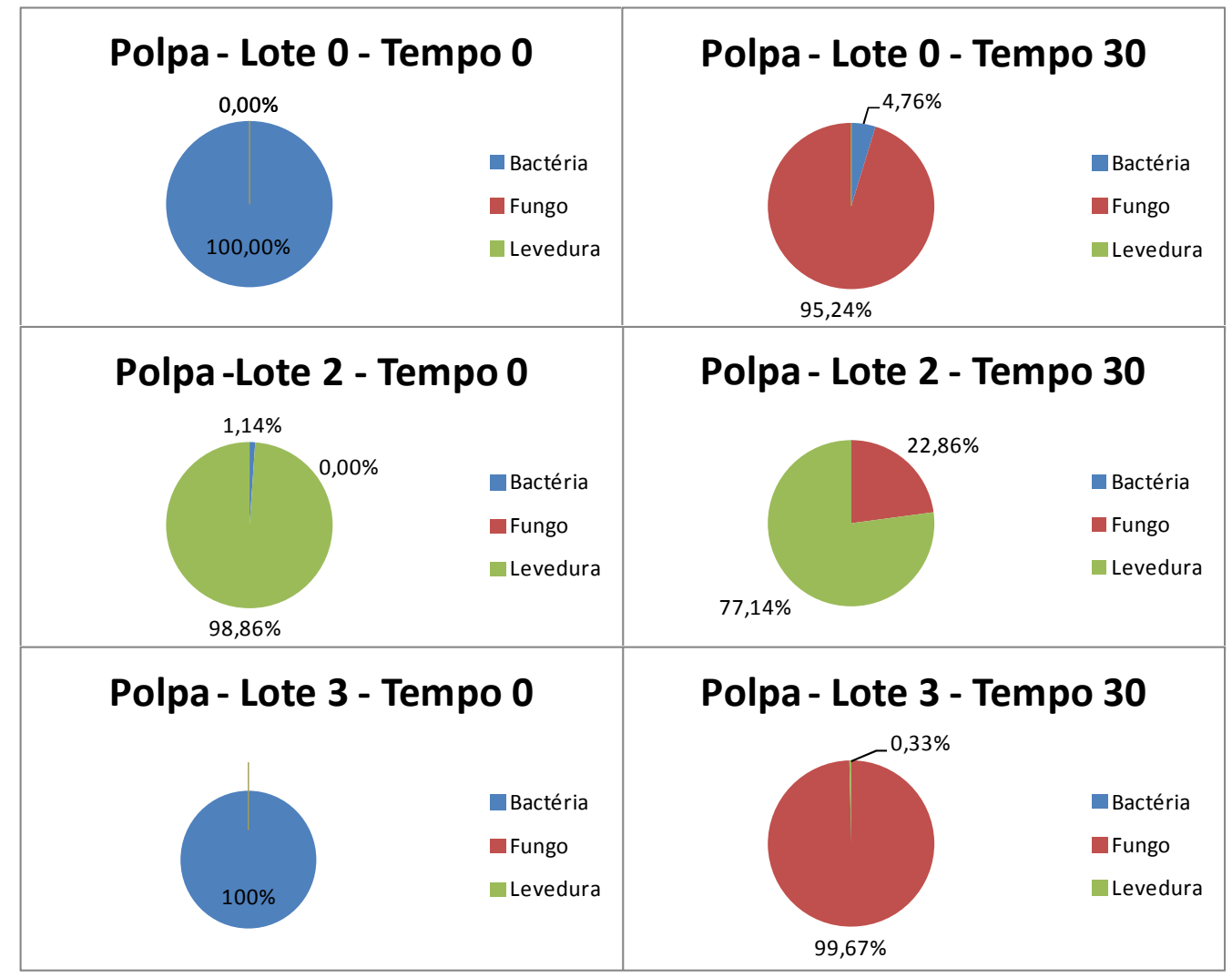

Figura 2 - Percentual de microrganismos na polpa.

Conforme Figura 2, no tempo "0", a polpa para os lotes 1 e 3 estava contaminada apenas por bactérias, havendo similaridade de resultado do que foi observado na casca nas mesmas condições. Contudo, após o armazenamento, praticamente apenas os fungos estavam presentes nesses lotes. Também com conformidade com o resultado encontrado na casca, para o lote 2, foi observado a predominância de leveduras tanto no tempo zero como após 30 dias de armazenamento, sendo um indicativo de que a lavagem seguida de imersão de em solução de hipoclorito é eficiente na redução de bactérias e fungos presentes. 
Em síntese, pode-se relatar que, após a coleta, independente do tratamento utilizado, tanto na casca quanto na polpa houve maior presença de bactérias e leveduras. Após o armazenamento, as leveduras e bactérias predominaram na casca da macaúba, enquanto que na polpa ocorreu uma maior contaminação pelos fungos.

O comportamento observado neste trabalho, em relação a redução do número de bactérias após o armazenamento foi semelhante ao observado por Pereira et al. (2013), onde tanto nos frutos sanitizados com solução de hipoclorito 400 ppm, quanto nos frutos sem tratamento a presença de bactérias foi reduzida com o tempo de armazenamento. Ainda segundo o autor, a população de fungos manteve-se estável durante todo o período de armazenamento avaliado, e a população de leveduras aumentou até 50 dias de armazenamento, extinguindo-se aos 120 dias. Nesses casos, o mesmo não foi observado neste trabalho.

A baixa umidade é uma das condições que favorecem o crescimento dos fungos. As leveduras necessitam de uma menor quantidade de água do que as bactérias, e maior quantidade do que os fungos (EVANGELISTA, 1994). Com o armazenamento houve uma grande redução do teor de umidade da polpa em todos os lotes (na faixa de 42 a 55\%), o que pode explicar a predominância de fungos na polpa no tempo “30”.

As diferenças do $\mathrm{pH}$ do alimento também influem consideravelmente sobre os microrganismos. Em caso de deterioração do alimento, o meio que antes era favorável à bactéria vai se tornando impróprio, à medida que produtos de decomposição se formam (EVANGELISTA, 1994). Neste trabalho não foi realizada a medida do $\mathrm{pH}$, mas é possível verificar que após trinta dias de armazenamento, quando as polpas estavam visivelmente em estado de degradação, houve uma diminuição da quantidade de bactérias presentes em todos os casos.

\section{CONCLUSÃO}

Os tratamentos utilizados não se mostraram efetivos para a não proliferação de microrganismos no fruto da macaúba no período de armazenamento de 30 dias. Mas todo o trabalho direciona para algumas orientações quando o objetivo for a preservação dos frutos. A recomendação de número zero reside na indicação de coleta seguido do processamento no menor tempo possível. A segunda recai na orientação de remoção quase que imediata dos frutos do chão para outro ambiente, podendo-se buscar locais com atmosferas que minimizem o crescimento de microrganismos.

\section{REFERÊNCIAS}

BRACKETT, R.E. Microbiological consequences of minimally processed fruits and vegetables. Journal of Food Quality, Trumbull, v.10, n.3, p.195-206, 1987.

CAMPBELL, G. S.; NORMAN, J. M. An Introduction to Environmental Physics. Springer, N. York, 286 p., 1998. 
CETEC - FUNDAÇÃO CENTRO TECNOLÓGICO DE MINAS GERAIS. Produção de combustíveis líquidos a partir de óleos vegetais: Estudo das oleaginosas nativas de Minas Gerais. Relatório Final do Convênio STI- MIC/CETEC, v. 1, 152 p., 1983.

EVANGELISTA, J. Tecnologia de alimentos. 2 impressão, 2 edição, Editora Atheneu, Rio de Janeirom 1994

LINARD, V. R.; NOCOLI, J. Produção de lípase a partir de microorganismos isolados de frutos de Macaúba (‥ Sclerocarpa). Trabalho não publicado, ICB/UFMG, 1981, Belo Horizonte.

MARTINS, A. D. Radiação Gama e secagem na conservação da qualidade do óleo de frutos de Macaúba. 2013. 109p. Dissertação (mestrado em Fitotecnia) - Departamento de Fitotecnia, Universidade Federal de Viçosa, Viçosa, 2013.

MOTA, C. S.; CORRÊA, T. R.; GROSSI, J. A. S.; CASTRICINI, A.; RIBEIRO, A. da S. Exploração sustentável da Macaúba para a produção de biodiesel: colheita, pós-colheita e qualidade dos frutos. Informe Agropecuário, Belo Horizonte: EPAMIG, v.32, n. 265, p. 41-51, nov./dez. 2011.

NUCCI, S. M. Desenvolvimento, caracterização e análise da utilidade de marcadores microssatélites em genética de população de Macaúba. 90p. Campinas. Dissertação (Mestrado em Agricultura Tropical e Subtropical) - Instituto Agronômico, Campinas, 2007.

PEREIRA, L. H. G.; FAVARO, S. P.; BANDEIRA, R.; COSTA, F. A. Avaliação da microbiota presente na polpa da Macaúba com ou sem sanitização durante armazenamento dos frutos. In: Congresso brasileiro de Macaúba: consolidação da cadeia produtiva, I, 2013, Patos de Minas, MG.

SILVA, C. E. L.; FARIAS, T. M.; ANDRADE, M. H. C.; RODRIGUES, M. N.; PEREIRA, M. da P. L.; RODRIGUES, G. R. Avaliação de métodos de sanitização para frutos da macaúba (Acrocomia aculeata) após colheita extrativista. In: CONGRESSO DA REDE BRASILEIRA DE TECNOLOGIA DE BIODIESEL, 4; CONGRESSO BRASILEIRO DE PLANTAS OLEAGINOSAS, ÓLEOS, GORDURAS E BIODIESEL, 7, 2010, Belo Horizonte.

SILVA, J. de C. Macaúba: fonte de matéria-prima para os setores alimentício, energético e industrial. 63p. Universidade Federal de Viçosa, Departamento de Engenharia Florestal, Viçosa, 2007.

TORTORA, G. J.; FUNKE, B. R.; CASE, C. L. Microbiology: an introduction. E. Pearson, 8 ed., 2004. 